\title{
COVID-19 in Italy: did the virus run on an ancient Roman road?
}

\author{
Elisa Maietti ${ }^{1} \cdot$ Davide Golinelli $^{1}$ [D $\cdot$ Maria Pia Fantini ${ }^{1}$ \\ Received: 9 May 2020 / Accepted: 15 September 2020 / Published online: 7 October 2020 \\ (C) Springer-Verlag GmbH Germany, part of Springer Nature 2020
}

\section{Background}

In late February 2020, Coronavirus disease-2019 (COVID19) (Rodriguez-Morales et al. 2020) had aggressively spread around many bordering provinces of the three most productive regions of northern Italy: Lombardy, Veneto, and Emilia Romagna (Onder et al. 2020), the Italian "economic engine" that accounts for $40.1 \%$ of the country's GDP (ISTAT 2020). The first outbreak exploded in the municipality of Codogno (Lombardy). Before the country's lockdown of 10 March 2020, the virus had indeed freely circulated throughout northern Italy and beyond. Sadly, some provinces' death toll currently (May 26, 2020) reflects a war bulletin (Nacoti et al. 2020), such as Bergamo (Lombardy, 1,114,590 inhabitants) and Piacenza (Emilia Romagna, 287,152 inhabitants) with 3085 and 944 deaths, and 11.62 and 15.55 cases per 1000 population, respectively (Italian Civil Protection 2020).

Emilia Romagna and Veneto showed a similar, though less dramatic, trend, compared to Lombardy, with provinces presenting a high number of cases and others, just a few kilometers $(\mathrm{km})$ away, with a lower incidence (Fig. 1). The latter is the case of Ferrara (Emilia Romagna, 345,691 inhabitants) and Ravenna (Emilia Romagna, 389,456 inhabitants), presenting a number of confirmed cases much lower than the other provinces ( 2.85 and 2.62 cases per 1000 population, respectively).

Ferrara has been indicated as an anomaly due to its very low number of cases in the first days of the Italian outbreak and several hypotheses have been put forward to explain it.

Davide Golinelli

davide.golinelli@unibo.it

1 Department of Biomedical and Neuromotor Sciences, Alma Mater Studiorum, University of Bologna, Via San Giacomo 12, 40126 Bologna, Italy

\section{The Ferrara anomaly}

The ancient city that hosted the Duchy of Este in the fifteenth and sixteenth centuries represents a real outlier. In fact, the data provided by the Civil Protection and Italian Ministry of Health (Italian Civil Protection 2020) clearly demonstrate that Ferrara is an area less affected by the infection with only 986 confirmed cases (total positive cases in Emilia Romagna: 27,587). What are the reasons for this anomaly? One of the hypotheses is the high prevalence of thalassemia/ microcythemia among the ferraresi, which may have protected the population as it did in the past century against malaria (Franceschini and Scutellari 2000). However, till now this theory does not have a convincing biological basis. Accordingly, we sought to test a geographical/behavioral hypothesis.

Currently, the cities of Emilia Romagna are culturally, socially, and economically connected through an ancient Roman road called Via Emilia (completed in 187 BC), that runs through the Po River valley (Pianura Padana) from Piacenza (16 km from Codogno) to Rimini (Adriatic coast) passing through Forlì, Bologna, Modena, Reggio Emilia, and Parma. The construction of the Via Aemilia launched the intensive Roman colonization of the Pianura Padana and soon rendered it the most economically important part of Italy. The area has remained economically preeminent in recent times, and the Via Emilia (also named on maps Highway 9-SS9) runs parallel to the main regional motorway (Motorway A1) and to the high speed railway line. Every day, a consistent number of people and goods moves along these important communication routes.

\section{Hypothesis}

We argue that the spread of the virus throughout Emilia Romagna has a possible explanation in the geographical location of most of its provinces along the Via Emilia, which we 
Fig. 1 COVID-19 infection rate per 1000 inhabitants for the nine provinces of the Emilia-Romagna region, Italy (May 25, 2020). Red shadow is the infection rate. Black line is the Via Emilia

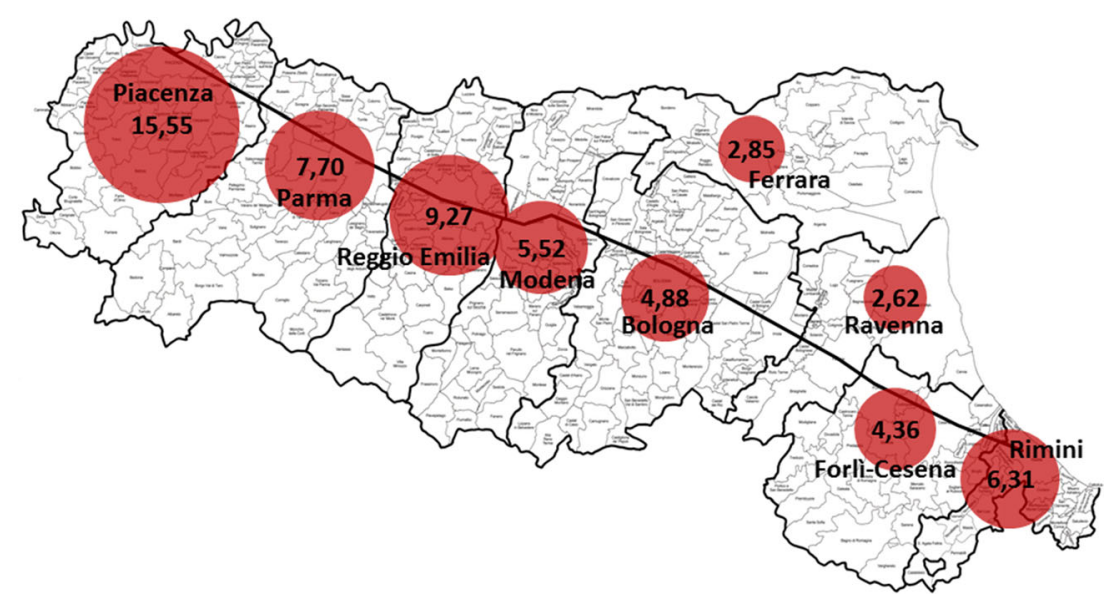

consider as a proxy for citizens' movement, number of contacts, and social interactions.

In order to test this hypothesis, we used a nonlinear multiple regression analysis on aggregate province data to investigate the association between the rates of confirmed cases and the distance from the Via Emilia (proportionally scored for every $10 \mathrm{~km}$ ), adjusted for the distance from the cluster of Codogno, the mean annual income, and the density of the population. Data were retrieved from different institutional sources. Ministry of Health for data on confirmed COVID-19 cases (Italian Civil Protection 2020), the National Institute of Statistics (ISTAT 2020) for data on provinces (number of residence and density of population) available until 2019, and Ministry of Economy and Finance for data on annual income, available until 2017. The analysis was conducted using Stata statistical software (StataCorp. 2019. Release 16. College Station, TX: StataCorp LLC.).

The results in Table 1 indicate that the infection rate decreases proportionally to the distance from Via Emilia $(-12 \%$ every $10 \mathrm{~km}, p<0.001)$. The other covariates contribute independently to the model, showing that the infection rate declines with the increase of the distance from Codogno and mean income and increases with density of the population.

Table 1 Results of nonlinear regression showing the relationship between the infection rate on 25 May 2020 and the other factors

\begin{tabular}{lccr}
\hline Variable & IRR & $95 \%$ CI & $p$ value \\
\hline Distance from SS9 $(+10 \mathrm{Km})$ & 0.88 & $0.84-0.93$ & $<0.001$ \\
Distance from Codogno $(+10 \mathrm{Km})$ & 0.93 & $0.91-0.94$ & $<0.001$ \\
Population income $(+500$ euro $)$ & 0.92 & $0.89-0.94$ & $<0.001$ \\
Population density $\left(+50\right.$ inhabitants $\left./ \mathrm{Km}^{2}\right)$ & 1.08 & $1.02-1.15$ & 0.013 \\
\hline
\end{tabular}

IRR, incidence rate ratio; $95 \% \mathrm{CI}, 95 \%$ confidence interval

\section{Conclusion}

The data on the spread of COVID-19 highlights that Ferrara and Ravenna have a lower vulnerability to the virus when compared to the other provinces. Ferrara is the most distant from the Via Emilia. Its "peculiarity" might have a geographical/behavioral explanation, due to its isolation from the regional main connection routes, which are still revolving around a road built by the ancient Romans 2000 years ago. Further studies are needed, but in order to stop the spreading of the virus, the Ferrara case may reinforce the evidence supporting measures of social distancing, which is a matter of discussion and concern worldwide.

Funding The authors declare that they are independent from any funders and that the study was carried out within their institutional work without any support from any third part.

Availability of data and material (data transparency) Data are publicly available.

The paper is accessible in preprint at: https:/www.preprints.org/ manuscript/202004.0513/v1

\section{Compliance with ethical standards}

Conflict of interest The authors declare that there are no conflicts of interest.

\section{References}

Franceschini F, Scutellari PN (2000) Beta-thalassemia. History began also in Ferrara. Radiol Med 2000 100(6):415-423. http://www. ncbi.nlm.nih.gov/pubmed/11307501

ISTAT (2020) Italian National Institute of Statistics data http:/dati.istat. it/. Accessed 2 April 2020

Italian Civil Protection (2020) Data http://www.protezionecivile.gov.it/. Accessed 26 May 2020

Nacoti M, Ciocca A, Giupponi A, Brambillasca P (2020) At the epicenter of the Covid-19 pandemic and humanitarian crises in Italy: changing 
perspectives on preparation and mitigation. N Eng J Med Catal Innov Care Deliv 2020:1-5. https://doi.org/10.1056/CAT.20.0080

Onder G, Rezza G, Brusaferro S (2020) Case-fatality rate and characteristics of patients dying in relation to COVID-19 in Italy. Jama 2020 2019:2019-2020. https://doi.org/10.1001/jama.2020.4683

Rodriguez-Morales AJ, Bonilla-Aldana DK, Balbin-Ramon GJ et al (2020) History is repeating itself, a probable zoonotic spillover as a cause of an epidemic: the case of 2019 novel coronavirus. Infez Med 2020 28(1):3-5

Publisher's note Springer Nature remains neutral with regard to jurisdictional claims in published maps and institutional affiliations. 